\title{
El control de las cláusulas abusivas como instrumento de intervención judicial en el contrato*
}

\author{
Rodrigo Momberg Uribe**
}

\section{RESUMEN}

A partir del estudio de jurisprudencia reciente, se analizan las facultades del juez en relación con el control de las cláusulas abusivas en contratos de adbesión. Se plantea que, no obstante, la ley faculta al juez solo para declarar la nulidad de una o más de tales cláusulas, los tribunales han también revisado el contenido de las mismas en caso de desequilibrio importante en las contraprestaciones, con el objeto de adaptar el contrato y restaurar dicho equilibrio. Lo anterior demuestra la insuficiencia de las facultades que la ley entrega al juez para el control efectivo de las cláusulas abusivas.

Cláusulas abusivas - contratos de adhesión - revisión del contrato

\section{The review of unfair terms as an instrument of judicial intervention in the contract}

\begin{abstract}
Based on a recent case study, this article analyzes the powers of the judge in relation to the control of unfair terms in contracts of adhesion. It argues that, although the law only authorizes the judge to invalidate one or more such provisions, courts have also reviewed their contents in case of relevant imbalance in their considerations, in order to adapt the contract and restore balance. This demonstrates the inadequacy of the powers that the law gives courts for the effective control of unfair terms.
\end{abstract}

Unfair terms - Contracts of adhesion - Contract review

* Este trabajo forma parte del proyecto FONDECYT regular No 1120611, titulado "La revisión judicial del contrato. Análisis histórico, dogmático y de derecho comparado, con perspectivas para el derecho nacional".

** Abogado, Doctor en Derecho, Profesor de Derecho Civil, Universidad Austral de Chile, Valdivia, Chile. Honorary Lecturer, Instituto Molengraaff de Derecho Privado, Universidad de Utrecht, Holanda. Correo electrónico: rmomberg@uach.cl.

Artículo recibido el 15 de marzo de 2013 y aceptado para su publicación por el Comité Editorial el 29 de mayo de 2013. 


\section{El JUEZ y EL CONTRATO EN EL DERECHO CHILENO. CONSIDERACIONES GENERALES}

$\mathrm{E}$ 1 principio de la fuerza obligatoria del contrato o pacta sunt servanda es uno de los pilares básicos del derecho de contratos, reconocido por la mayoría de los ordenamientos jurídicos y consagrado positivamente tanto en las codificaciones decimonónicas como en las contemporáneas. Dicho principio, lo mismo que los principios de libertad contractual y del efecto relativo de los contratos, se considera el corolario necesario del dogma de la autonomía de la voluntad ${ }^{1}$. En términos generales, la fuerza obligatoria del contrato implica que las partes deben respetar las obligaciones que válidamente han contraído, teniendo estas fuerza vinculante para ellas y por tanto exigibilidad para su cumplimiento. En su concepción tradicional supone también la intangibilidad del contrato, de manera que ni las partes (con la obvia excepción del mutuo consentimiento) ni el juez pueden variar los términos de un contrato válidamente celebrado, independientemente de cuánto hayan cambiado las condiciones presentes a la celebración del mismo. La protección de la libertad individual y la seguridad jurídica son considerados bajo este prisma como valores absolutos a ser amparados por el derecho. En el enfoque tradicional, lo anterior supone que la tarea del ordenamiento jurídico es garantizar la justicia formal del proceso de formación del consentimiento, lo que implica que el acuerdo a que lleguen las partes bajo esas condiciones de justicia formal sea también considerado justo en términos sustantivos, ya que se entiende que las partes actúan en un plano de igualdad y libertad para determinar el contenido del contrato $^{2}$. Además, la prevalencia de la autonomía de la voluntad supone también que, en caso que este sea afectado por algún vicio en su formación, ello conlleve a su extinción a través de la nulidad o la rescisión, pero en ningún caso a su modificación.

De esta manera, la intervención de un tercero en un contrato que se supone ha sido celebrado libre e informadamente por partes en igualdad de condiciones, implicaría una interferencia ilegítima a la autonomía de las partes y por tanto un atentado a la justicia formal del acuerdo y a la seguridad jurídica en general. La revisión y eventual adaptación del contrato por el juez supondría vulnerar la libertad individual de las partes, manifestada en los términos explícitos e implícitos del acuerdo celebrado, el cual solo podría ser modificado por el consentimiento mutuo de los contratantes ${ }^{3}$. Siendo el contrato la ley privada de las partes, ellos deben someterse al mismo sin consideración a que las condiciones en las cuales se ejecute el acuerdo sean sustancialmente distintas a las de su celebración.

Esta concepción, asociada a la doctrina liberal clásica de los siglos XVIII y XIX, sumada a la circunstancia de los abusos cometidos por los tribunales del ancien régime,

\footnotetext{
${ }^{1}$ López, J., Los contratos: parte general, Ed. Jurídica de Chile, Santiago, 2001.

${ }^{2}$ Zimmermann, R., The law of obligations: Roman foundations of the civilian tradition, Oxford University Press, Oxford, 1996.

${ }^{3}$ Dawson, J., "Judicial Revision of Frustrated Contracts: The United States", Boston University law review 64, 1, 1984.
} 
hizo que las codificaciones del siglo XIX restringieran en términos casi absolutos la intervención del juez en las relaciones privadas y particularmente en materia de contratos ${ }^{4}$. El ejemplo paradigmático lo constituye el Código Civil francés, que en su artículo 1134 consagró la regla de equiparar el contrato a una ley privada para los contratantes, regla que serviría de modelo para muchos otros códigos posteriores, incluido el chileno 5 .

Así, el artículo 1545 de nuestro Código Civil consagra en plenitud el dogma de la autonomía de la voluntad y el principio de la fuerza obligatoria del contrato: "Todo contrato legalmente celebrado es una ley para los contratantes, y no puede ser invalidado sino por su consentimiento mutuo o por causas legales". Esta norma es considerada por parte importante de la doctrina como el principal obstáculo para admitir la revisión judicial del contrato. En este sentido, a propósito de la admisibilidad de la teoría de la imprevisión, se ha señalado que el citado artículo solo permite la adaptación del contrato por la voluntad de ambas partes o por causas legales, no habiéndose otorgado al juez la facultad de modificar las convenciones ${ }^{6}$. Sin perjuicio de lo anterior, debe precisarse que actualmente la tendencia parece ser a la morigeración del alcance absoluto del artículo 1545, especialmente a través de la aplicación del principio de buena fe en la ejecución de los contratos ${ }^{7}$ y de una renovada interpretación histórica y dogmática de la mencionada norma ${ }^{8}$.

Por otra parte, tradicionalmente la jurisprudencia nacional se ha mostrado contraria a admitir (al menos de manera expresa) la facultad del juez de revisar lo acordado por las partes. La sentencia clásica citada al efecto es la de fecha 10 de enero de 1925, en la cual la Corte Suprema señaló expresamente que “...los tribunales carecen de facultades para derogar o dejar sin cumplimiento la ley del contrato, ya sea por razón de equidad o bien de costumbres o reglamentos administrativos..."9.

Sin perjuicio de lo anterior, algunos autores han argumentado que en casos excepcionales los tribunales han procedido a revisar y modificar relaciones contractuales sometidas a su consideración, aun cuando los fallos no lo admitan de manera explícita. Así, se citan casos de nulidad parcial, introducción de índices de reajustabilidad en contratos que originalmente no los contemplaban, supresión de índices de reajustabilidad

${ }^{4}$ Ghestin, J., Le prix dans les contrats de longue durée. LGDJ, Paris, 1990.

${ }^{5}$ El artículo 1134 del Código Civil francés dispone: "Les conventions légalement formées tiennent lieu de loi à ceux qui les ont faites. Elles ne peuvent être révoquées que de leur consentement mutuel, ou pour les causes que la loi autorise. Elles doivent être exécutées de bonne foi”.

${ }^{6}$ Abeliuk, R., Las obligaciones, 4a Edición, Ed. Jurídica de Chile, Santiago, 2001, pp. 762-763.

${ }^{7}$ Fueyo, F., "La ejecución de buena fe, del art. 1546 del Código Civil, es uno de los requisitos legales del pago y como tal se proyecta como fundamento de la indexación y desindexación”, en Fueyo, F. (Ed.), Instituciones De Derecho Civil Moderno. Ed. Jurídica de Chile, Santiago, 1990.

${ }^{8}$ Peñailillo, D., "La revisión judicial de obligaciones y contratos en la reforma del Código Civil: la lesión y la imprevisión", Revista de derecho (Concepción), 2000, pp. 209-237; Barcia R., "La autonomía privada como principio sustentador de la teoría del contrato y su aplicación en Chile”, en Temas de Contratos. Cuadernos de análisis jurídico, Colección Derecho Privado III, Ediciones Universidad Diego Portales, Santiago, 2006.

${ }^{9}$ RDJ, t. 23, sección primera, p. 423. 
expresamente pactados y reajuste de pago de remuneración a base de un porcentaje de utilidades para corregir la desvalorización de la moneda ${ }^{10}$.

No obstante lo anterior, en otros casos la Corte Suprema ha mantenido invariable la vigencia del principio nominalista, aun reconociendo lo injusto de la solución ${ }^{11}$. En este sentido, en una sentencia del año 2009, en la cual el máximo tribunal se hace cargo de la procedencia de la teoría de la imprevisión en nuestro ordenamiento jurídico, la Corte señaló expresamente que el artículo 1545 del Código Civil excluye la posibilidad de acoger dicha teoría, ya que "el contrato no puede ser dejado sin efecto, y con menos razón aún modificado, si no es por voluntad de las partes - los jueces en materia civil no tienen otras facultades que las que se les han otorgado, y nadie les ha dado la de modificar las convenciones" 12 .

\section{El CONTROL de las Cláusulas abusivas y LA INTERVENCIÓN DEL JUEZ EN EL CONTRATO}

Una de las situaciones en que los postulados expresados en el apartado anterior pierden fuerza, para dar paso a restricciones de la libertad contractual en su sentido clásico, es el caso de los contratos de adhesión y, en particular, del control de las cláusulas abusivas contenidas en ellos. En este sentido, la mayoría de las legislaciones contemporáneas han incorporado algún mecanismo de control respecto de tales cláusulas, permitiendo en mayor o menor medida la intervención de un tercero ajeno, por lo general el juez, en el contenido del contrato. No es objetivo de este trabajo analizar los fundamentos de dicha intervención ni los mecanismos establecidos para su control, sino exponer cómo se ha manifestado en Chile la intervención judicial del contrato por medio del control de las cláusulas abusivas ${ }^{13}$.

En este sentido, a nivel de Corte de Apelaciones, en los últimos años se ha ido asentando una jurisprudencia que en rigor implica la modificación de contratos vigentes, a través del control de cláusulas abusivas, tanto en casos de contratos de consumo como (en menor medida) de contratos civiles y comerciales. El fundamento último de estas sentencias ha sido en todos los casos la excesiva desproporción entre las contraprestaciones,

${ }^{10}$ Véase, Fueyo (nota 7); Elorriaga, F., "La nulidad parcial”, en Revista de Derecho y Jurisprudencia, Edición Bicentenario, Doctrinas Esenciales, Santiago, Editorial Jurídica, 2010; Barcia, R., “¿Es posible construir la teoría general del contrato desde la excepción? La revisión judicial del contrato”, en Sesquicentenario del Código Civil de Andrés Bello: Pasado, Presente y Futuro de la Codificación, LexisNexis, Santiago, 2005, pp. 685-719.

${ }^{11}$ López, J., Las obligaciones y contratos frente a la inflación, Ed. Jurídica de Chile, Santiago, 1978.

${ }^{12}$ Corte Suprema, 9 de septiembre de 2009, recurso de casación en el fondo, South Andes Capital S.A. c/ Empresa Portuaria Valparaíso, Rol 2651-08. Véase Momberg, R., "Teoría de la imprevisión: la necesidad de su regulación legal en Chile”, Revista Chilena de Derecho Privado, N 15, 2010; con referencia también a jurisprudencia arbitral y administrativa.

${ }^{13}$ Para el análisis de los fundamentos del control de las cláusulas abusivas en los contratos de adhesión, me remito al excelente trabajo de De la Maza, I., "Contratos por adhesión y cláusulas abusivas ¿Por qué el Estado y no solamente el mercado?”, en Revista Chilena de Derecho Privado, No 1, 2003, pp. 109-148. 
lo cual podría interpretarse como una renovada visión judicial en cuanto a controlar no solo la justicia formal del acuerdo, sino también su justicia material o substantiva.

Así, en materia civil, en una sentencia del 4 de junio de 2010, la Corte de Apelaciones de Santiago decretó la nulidad de cláusula penal establecida en un contrato de subarrendamiento $^{14}$. En el considerando 12 la Corte señaló que "del contrato aparece de manifiesto la falta de reciprocidad en las obligaciones y derechos de ambos contratantes, con desequilibrio importante para una de ellas y afectación de principios básicos de la libertad contractual, que impiden se considere la existencia de un justo equilibrio de las contraprestaciones, generando en consecuencia una cláusula abusiva a la que debe privarse de validez, en cuanto ella obliga a pagar al demandado por concepto de avaluación anticipada de perjuicios el $50 \%$ de las rentas pendientes de vencimiento al momento del incumplimiento, sin que ello altere la vigencia de la obligación principal”. Es curioso que la única norma citada para fundar la decisión fuese el artículo 1683 del CC, lo que hace presumir que la sanción impuesta por la Corte fue la nulidad absoluta. No hay referencia a la causal específica de nulidad (el art. 1682 del CC no aparece citado en el fallo) y del examen de la sentencia no es fácil deducirla, pudiendo quizás configurarse un caso de objeto o causa ilícita, análisis que sobrepasa por mucho el ámbito de este estudio. Por último, es relevante hacer notar que la Corte no recurre al artículo 1544 del CC, el cual regula justamente los casos de cláusula penal enorme, concediendo al juez la facultad de rebajar o moderar la cláusula penal en determinados casos.

En materia de protección al consumidor existen también fallos interesantes. Así, en un fallo de 21 de septiembre de 2007 nuevamente la Corte de Apelaciones de Santiago estableció que basándose en la letra g) del art. 16 de la LPC, eran nulas las estipulaciones del Reglamento asociado a un contrato de tiempo compartido, que establecían las obligaciones de pagar cuotas de membresía (valor anual para mantener la calidad de socio en caso de no utilizar el sistema vacacional) y de servicio (valor adicional por cada semana de utilización del sistema vacacional). La Corte estimó que tales cláusulas constituían incrementos del precio convenido, que no se compadecían con las expectativas razonables del adherente, atendida la finalidad del contrato, generando un desequilibrio importante entre las partes ${ }^{15}$.

En el mismo fallo se decretó la nulidad de la cláusula penal, por ser desproporcionadamente favorable para el proponente. Señala la sentencia "Que las últimas modificaciones introducidas a la Ley de Protección de los Derechos del Consumidor, permiten ejercer un mayor control del contenido de los contratos de adhesión, con el objeto de evitar las cláusulas abusivas que alteren en forma desproporcionada el equilibrio del contrato y favorezcan irracionalmente al oferente. Estas normas amplían el orden público de protección, estableciendo una enumeración de cláusulas que se consideran abusivas -artículo 16, de las letras a) a la f) y una definición general, en la letra g)-, que permite incorporar otros casos no contemplados expresamente en esa enunciación, por la vía de verificar si existe

\footnotetext{
${ }^{14}$ Corte de Apelaciones de Santiago, 4 de junio de 2010, Rol 5484-2009, MJCH_MJJ24103.

15 Corte de Apelaciones de Santiago, 21 de septiembre de 2007, Rol 3746-2007, MJCH_MJJ15681.
} 
un desequilibrio importante entre los derechos y obligaciones de las partes, situación que se vincula, en forma expresa, a la buena fe y a la finalidad del contrato. Para determinar la finalidad del contrato, se ha entendido que se deben examinar las expectativas que el consumidor, razonablemente, podría haberse hecho respecto del contrato, lo que implica que uno de los principales elementos para limitar el contenido abusivo de los contratos por adhesión se encuentra en la noción de defraudación de expectativas del adherente" (Considerando $1^{\circ}$ ). La sentencia nuevamente sitúa el énfasis en el examen de la proporcionalidad entre los derechos y obligaciones de las partes, criterio que parece ser el determinante para declarar una cláusula como abusiva.

En otra sentencia, la Corte de Apelaciones de Copiapó estableció la nulidad de una cláusula penal por ser extremadamente favorable solo para el promitente vendedor, ya que la cláusula generaba una desproporción contraria al concepto de buena fe contemplado en el art. 16 letra g), causando un desequilibrio importante en los derechos y obligaciones de las partes, lo que según la Corte no resulta aceptable conforme a las normas de equidad que deben existir en las estipulaciones y en el cumplimiento de los contratos de adhesión ${ }^{16}$.

La Corte de Apelaciones de Santiago, en dos sentencias muy próximas temporalmente, decretó la nulidad de las cláusulas que en sendos contratos de educación obligaban al pago del arancel aun cuando el alumno (matriculado) no utilizara los servicios educacionales ${ }^{17}$. En ambas sentencias, uno de los fundamentos para acoger la acción fue que tal cláusula causaba un desequilibrio importante en los derechos y obligaciones de las partes en el contrato. Asimismo, en ambos fallos, al citarse el artículo 16 de la Ley $\mathrm{N}^{\circ} 19.496$ se omite la referencia a la buena fe como criterio para el establecimiento de la abusividad de las cláusulas. Así por ejemplo, el segundo de los fallos citados señala que "el párrafo 4 [de la Ley No 19.496] se inicia con el artículo 16, que dispone que "no producirán efecto alguno, entre otras, las cláusulas que "en perjuicio del consumidor causen "un desequilibrio importante en los derechos y obligaciones que para las partes se deriven del contrato. El precepto añade que, para ello, 'se atenderá a la finalidad del contrato y a las disposiciones especiales o generales que lo rigen'” (Considerando $6^{\circ}$ ).

En las sentencias referidas anteriormente la intervención judicial en el contrato se ha manifestado en la nulidad de ciertas cláusulas, lo cual implica una modificación contractual en el sentido que parte del contrato celebrado por las partes es dejado sin efecto, alterando en ese sentido la vigencia del acuerdo original. No obstante, ninguna de las mencionadas sentencias implicó, en estricto rigor, que los tribunales modificaran el contenido de una o más de las cláusulas estipuladas, adaptándola para que rigiera hacia el futuro en una manera distinta a la pactada por las partes.

Sin embargo, una reciente sentencia de la Corte de Apelaciones de Santiago, de fecha 14 de mayo de 2012, ha establecido una doctrina novedosa y que rompe claramente con

${ }^{16}$ Corte de Apelaciones de Copiapó, 16 de agosto de 2010, Rol 24-2010, CL/JUR/4774/2010.

17 Corte de Apelaciones de Santiago, 1 de julio de 2008, Rol 8775-2004, CL/JUR/5490/2008; y 5 de julio de 2008, Rol 2335-2008, CL/JUR/5492/2008. 
nuestra tradición sobre la intangibilidad del contrato por los tribunales ${ }^{18}$. En el caso, se solicitó se declarasen abusivas algunas de las cláusulas contenidas en un contrato de prestación de servicios educacionales celebrado con una universidad, por violación al artículo 16 de la LPC. De particular interés resulta la petición de la denunciante que se declarase abusiva la cláusula segunda del contrato que señalaba que Si el alumno debe repetir una o más asignaturas o han vencido los plazos reglamentarios y con ello se altera el orden, número de ramos y horarios de asistencia a clases de las asignaturas que debe cursar o a las que ha optado, será su exclusiva responsabilidad y no dará lugar a variaciones en el valor de la matrícula ni de la colegiatura. La estudiante, quien debía repetir solo el último ramo de su carrera, alegó que dicha cláusula infringía el equilibrio de las prestaciones del contrato exigido por el artículo 16 letra g) de la LPC, ya que el pago del arancel completo no se condecía con la prestación del servicio por parte de la universidad cuando solo debía rendirse un ramo (y no cinco, como en un semestre normal).

Conociendo de la causa en segunda instancia, la Corte de Apelaciones de Santiago dicta una sentencia inédita en cuanto a la interpretación de los artículos 16 letra g) y 16A de la LPC, ya que no solo declara abusivas determinadas cláusulas del contrato sometido a su consideración, sino que además, respecto de la mencionada cláusula segunda, rebaja el monto del arancel anual que debía pagar la demandante al equivalente al $20 \%$ de su valor, por considerarlo proporcionado al único ramo cursado por la actora en dicho año.

De esta manera, la Corte, aludiendo a la conmutatividad de las obligaciones, modifica y adapta un contrato en el sentido de rebajar la prestación debida por una de las partes, en razón, a su juicio, de haberse producido un desequilibrio en la economía del contrato.

Al fundamentar su decisión, la Corte señaló respecto de la ya citada cláusula segunda, que dicha estipulación infringía el artículo 16 letra g) de la LPC, ya que su contenido "atenta contra parámetros de buena fe objetiva -que es exigida por esa norma-, desde que con ella[s] se altera el equilibrio de las prestaciones, atendido lo exigente e inflexible de ese contenido y la clara desigualdad que existe en este caso entre proveedor y consumidor" (Considerando Segundo). Agrega la Corte que la mencionada norma "reconoce el principio de la conmutatividad de las obligaciones al señalar que son abusivas las cláusulas, en especial, que constituyen un desequilibrio importante en los derechos y obligaciones de los intervinientes..." (Considerando Cuarto).

La jurisprudencia citada, y en particular la última sentencia, dan lugar a una serie de interrogantes y reflexiones, que serán tratadas a continuación. La primera, determinar cuándo debe entenderse que una cláusula causa un desequilibrio importante en los derechos y obligaciones de las partes, según lo establece la letra g) del artículo 16 de la Ley $\mathrm{N}^{\circ}$ 19.496. La segunda, definir cuáles son las facultades de los tribunales respecto de las cláusulas abusivas en los contratos de adhesión, en especial si estas incluyen no solo la declaración de nulidad de tales cláusulas, sino también su adaptación. Por último, relacionada con la anterior, establecer los parámetros a que debería sujetarse la modificación judicial del contrato. 


\section{El DESEquilibrio ENTRE las PRESTACiOnes Como FACTOR DE DETERMINACIÓN DE LAS CLÁUSULAS ABUSIVAS}

Pese a su evidente relevancia, al establecer una causal genérica de abuso sujeta principalmente a la discreción judicial, la doctrina nacional ha analizado poco la causal contenida en la letra g) del artículo 16 de la LPC $^{19}$. Dicha norma dispone que:

No producirán efecto alguno en los contratos de adhesión las cláusulas o estipulaciones que: g) En contra de las exigencias de la buena fe, atendiendo para estos efectos a parámetros objetivos, causen en perjuicio del consumidor, un desequilibrio importante en los derechos $y$ obligaciones que para las partes se deriven del contrato. Para ello se atenderá a la finalidad del contrato y a las disposiciones especiales o generales que lo rigen. Se presumirá que dichas cláusulas se encuentran ajustadas a exigencias de la buena fe, si los contratos a que pertenecen han sido revisados y autorizados por un órgano administrativo en ejecución de sus facultades legales.

Al efecto, se ha señalado que esta regla requiere conjuntamente la vulneración a la buena fe y el desequilibrio importante en las contraprestaciones, sin perjuicio que la existencia del desequilibrio pueda implicar una especie de presunción de mala fe por parte del predisponente ${ }^{20}$.

Se agrega que la buena fe objetiva a que se refiere la norma se traduce en el deber de comportarse correcta y lealmente, más precisamente, en la observancia de las exigencias que imponen las convicciones éticas imperantes en el tráfico comercial. Se trataría entonces de una manifestación de la justicia procedimental, y no sustantiva, que debe seguirse tanto en la fase de redacción como de celebración del contrato, evitando en general que se establezcan por parte del proveedor cláusulas que no se relacionen con las expectativas razonables del consumidor o con la finalidad normal del contrato ${ }^{21}$.

En relación con el "desequilibrio importante" entre las contraprestaciones, se dice que debe ser efecto de la contravención a la buena fe objetiva. Si bien su determinación queda entregada a la discreción del juez, la norma entrega dos criterios que deben tenerse en cuenta:

- La finalidad del contrato, y

- Las disposiciones generales y especiales que lo rigen

Ambos criterios pueden refundirse en la necesidad que el contrato responda efectivamente al objeto típico que satisfaga las expectativas razonables que el consumidor

${ }^{19}$ Destaca especialmente el trabajo de De la Maza, I., "El control de las cláusulas abusivas y la letra g)", Revista Chilena de Derecho Privado, No 3, 2004, pp. 35-68.

${ }^{20}$ Ibidem.

${ }^{21}$ Ibidem. 
pretende realizar con su celebración ${ }^{22}$. La consideración de estos criterios por el juez no obsta a que pueda tomar en cuenta otros, de manera complementaria.

La exigencia conjunta de una desproporción significativa entre las contraprestaciones y la vulneración a la buena fe para considerar como abusiva a una cláusula no es una cuestión pacífica en derecho comparado.

Así, el Code de la Consommation francés hace solo referencia al desequilibrio entre las contraprestaciones al definir lo que es una cláusula abusiva, no incluyendo la vulneración de la buena fe en dicha definición. El artículo L.132-1 de dicho Código dispone que "En los contratos celebrados entre profesionales y consumidores o personas no profesionales, se reputarán abusivas las cláusulas cuyo objeto o efecto consista en producir, en perjuicio del consumidor o persona no profesional en cuestión, una desigualdad significativa entre los derechos y obligaciones de las partes contratantes" ${ }^{23}$. Comentando esta norma, se ha dicho que si las cláusulas abusivas tienen el efecto de crear un desequilibrio significativo entre los derechos y obligaciones de las partes, es superfluo preguntarse si fueron estipuladas contrariando las exigencias de la buena $\mathrm{fe}^{24}$.

En el mismo sentido, el Código de Defensa del Consumidor de Brasil establece en su artículo 51.IV que se consideran cláusulas abusivas aquellas que "establezcan obligaciones consideradas inequitativas, abusivas, que coloquen al consumidor en desventaja exagerada, o sean incompatibles con la buena fe o la equidad". Esta norma ha sido interpretada en el sentido de incluir criterios complementarios pero independientes (la existencia de una desventaja exagerada para el consumidor por una parte, y por otra, la incompatibilidad con la buena fe o la equidad) para la determinación de la abusividad de una cláusula contractual ${ }^{25}$.

Asimismo, la inclusión conjunta de la buena fe y del desequilibrio importante en la definición de cláusula abusiva de la Directiva Europea 93/13, ha sido criticada por considerarse una estructura innecesariamente compleja, que ha producido reiterados debates respecto de su interpretación, en especial en relación con la necesidad de la exigencia copulativa de ambos criterios para la determinación de abusividad de una cláusula ${ }^{26}$. Sin perjuicio de estos cuestionamientos, la reciente propuesta para un Reglamento relativo a una Normativa Común de Compraventa Europea ${ }^{27}$ exige en su artículo 83, para determinar si una cláusula es abusiva en contratos celebrados entre un

\footnotetext{
${ }^{22}$ Ibídem.

${ }^{23}$ Traducción disponible en http://www.legifrance.gouv.fr/content/download/1972/13775/version/2/ file/Code_48.pdf

${ }^{24}$ Mazeaud, Denis, "La loi du 1er février 1995 relative aux clauses abusives: véritable réforme ou simple réformette?", Droit et Patrimoine, junio 1995, № 18, p. 47; citado por Stiglitz, Rubén, "Contrato de consumo y cláusulas abusivas", Contexto, No 4, 1999, p. 41.

${ }^{25}$ Lima Marques, C., Contratos no Código de Defesa do Consumidor, Editora Revista dos Tribunais, São Paulo, 2011, 6a. Ed., p. 974.

${ }^{26}$ Meli, M., "Unfair Terms and Unfairness Test in Contracts between Businesses and Consumers", en Somma, A. (ed.), The Politics of the Draft Common Frame of Reference, Kluwer Law International, Alphen aan den Rijn, 2009.

${ }^{27} \operatorname{COM}(2011) 635$ final.
} 
proveedor y un consumidor, que aquella cause, en contra de las exigencias de la buena fe contractual y en detrimento del consumidor, un desequilibrio significativo en los derechos y obligaciones de las partes. Nuevamente la norma ha sido criticada por la exigencia conjunta de ambos elementos, ya que se entiende que una cláusula que cause una ventaja injustificada y significativa a favor del proveedor es absolutamente incompatible con la idea de buena fe contractual. Se agrega que el carácter abstracto del concepto mismo de buena fe puede generar interpretaciones diversas en cuanto a su significado en el caso concreto, afectando la predictibilidad y certeza de las decisiones judiciales ${ }^{28}$.

Tal como se expuso, existe una tendencia incipiente pero constante en la jurisprudencia nacional a examinar el contenido del contrato en relación con el equilibrio de las contraprestaciones. Las sentencias mencionadas en el apartado anterior parecen entender que es la desproporción significativa en las contraprestaciones la que configura una contravención a la buena fe, y no, como ha entendido la doctrina, que dicho desequilibrio debe ser efecto de la contravención a la buena fe objetiva. De ello puede concluirse que el elemento esencial utilizado por los tribunales para la determinación de la abusividad es la existencia de una desproporción significativa entre las contraprestaciones, la cual acarrearía la contravención a la buena fe por parte del predisponente.

Lo anterior parece adecuado. Hay que recordar que en la relación contractual de consumo se caracteriza por su desequilibrio estructural a favor del proveedor, especialmente en relación con el contenido técnico y jurídico del contrato, conocimiento que justamente le permite predisponer el contenido contractual para ofrecerlo al consumidor, al cual solo le es posible aceptar o rechazar dicha oferta, sin posibilidad de negociar. De esta manera, si la parte aventajada técnica, económica y jurídicamente diseña el contenido del contrato de modo tal de permitirle obtener ventajas excesivas e injustificadas en detrimento de la contraparte, esa sola circunstancia debería ser demostrativa de abuso y por tanto sancionada por el ordenamiento jurídico, sin que sea necesario examinar la buena o mala fe del predisponente ${ }^{29}$.

La exigencia de una (relativa) conmutatividad no es completamente ajena a nuestro derecho de contratos. Es cierto que nuestro Código Civil no estableció a la lesión como un vicio de carácter general, pero ello no obsta a que pueda sostenerse que una excesiva desproporción entre los derechos y obligaciones de las partes, tomando en consideración y evaluando al contrato en su conjunto y no solo en la relación objeto/precio, sea inocua. Así, la mantención de la conmutatividad del contrato ha sido ya alegada por la doctrina para justificar, por medio del artículo 1441 del Código Civil, la admisibilidad de la teoría de la imprevisión en el derecho privado chileno, señalándose al afecto incluso que "en los contratos onerosos conmutativos es también de su esencia la equivalencia de las prestaciones" 30 . A base de la norma citada, se puede afirmar que tratándose de

${ }^{28}$ Mazeaud, D. y Sauphanor-Brouillaud, N., "Unfair contract terms", en Schulze, R. (ed.), Common European Sales Law - Commentary, Nomos Verlagsgesellschaft, Baden-Baden, 2012.

${ }^{29}$ Estas ideas presentan ciertas similitudes con la denominada concepción objetiva-subjetiva de la lesión. Véase Peñailillo (nota 8), pp. 217-218.

${ }^{30}$ Dörr, J.C. “Notas acerca de la teoría de la imprevisión”, Revista Chilena de Derecho, V. 12, 1985, p. 266. 
un contrato conmutativo, debe existir una cierta equivalencia entre la posición de las partes en relación con el contenido del contrato, más aún si se parte del supuesto que existe un desequilibrio estructural o posición aventajada para una de ellas, como sucede en los contratos de consumo ${ }^{31}$. En este sentido, puede sostenerse que es tarea del ordenamiento corregir esta situación de desequilibrio y evitar que la ventaja natural de una de las partes se transforme en abuso jurídico para la otra.

\section{La naturaleza de las Cláusulas sometidas al CONTROL DEL JUEZ}

Las cláusulas declaradas nulas en las sentencias citadas en el párrafo II de este trabajo incluyen tanto cláusulas que se relacionan con el objeto principal del contrato como otras que establecen obligaciones secundarias o accesorias.

Por ello, en relación con las cláusulas que el juez puede examinar, resulta relevante, en atención a los fallos citados, determinar si las cláusulas que constituyen el objeto principal del contrato (precio y bien o servicio) están también sujetas al control judicial. Se ha sostenido que tales cláusulas están fuera del examen del juez, ya que la intervención del juez supondría atentar contra libertad de mercado, en especial, la libre fijación de precios. De esta manera, no cabe examinar la adecuación o equilibrio entre el bien o servicio prestado por el proveedor, y el precio pagado por el consumidor. Al efecto, se señala que el desequilibrio sancionado es de tipo jurídico y no económico ${ }^{32}$. Se sostiene además que son justamente estas las cláusulas a las cuales el consumidor ha prestado atención, y eventualmente negociado ${ }^{33}$.

Sin embargo, se ha destacado acertadamente también que en algunos casos es difícil establecer una distinción clara entre el control de cláusulas abusivas y el control de contratos abusivos, especialmente cuando en cláusulas del contrato distintas de aquellas que constituyen su objeto principal se establecen por el proveedor cargos o aumentos en el valor del servicio que no forman (al menos materialmente) parte del precio pacta$\mathrm{do}^{34}$. En esas situaciones, la revisión de tales cláusulas puede implicar en el hecho una revisión del precio.

En derecho comparado, la Directiva europea 93/13 sobre cláusulas abusivas dispone en su artículo 4.2 que la apreciación del carácter abusivo de las cláusulas no se referirá a la definición del objeto principal del contrato ni a la adecuación entre precio y retribución, por una parte, ni a los servicios o bienes que hayan de proporcionarse como contrapartida por otra, siempre que dichas cláusulas se hayan redactado de manera clara y comprensible.

${ }^{31}$ En el caso de contratos comerciales o civiles propiamente tales, puede sostenerse que las partes actúan desde un plano de igualdad, de manera que no cabe otorgar protección especial a ninguna de ellas, y lo que resulte del contrato (equilibrado o no) será fruto de una negociación entre pares, de manera que no cabe su examen a posteriori. La cuestión es discutible, pero excede el objeto del presente trabajo.

32 De la Maza (nota 19).

33 Stiglitz (nota 24), p. 40.

${ }^{34}$ Whittaker, S., "Unfair Contract Terms, Unfair Prices and Bank Charges”, The Modern Law Review, (2011) 74(1), p. 122. 
Sin embargo, la Directiva se basa en el principio de la armonización mínima, en virtud del cual los Estados miembros pueden adoptar en sus legislaciones nacionales medidas más estrictas que las señaladas en la Directiva, es decir, otorgar mayores derechos a los consumidores. Además, en los considerandos de la misma Directiva se señala que para la apreciación del carácter abusivo de otras cláusulas podrán tenerse en cuenta el objeto principal del contrato y la relación calidad/precio.

Así, en España, el Texto Refundido de la Ley General para la Defensa de los Consumidores y Usuarios (LGDCU) no excluye expresamente del control del juez a las cláusulas que constituyen el objeto principal del contrato. Su artículo 80 letra c) dispone que uno de los requisitos que deben cumplir los contratos de adhesión con consumidores es el de la buena fe y justo equilibrio entre los derechos y obligaciones entre las partes. Resolviendo una cuestión prejudicial planteada por el TS español, el Tribunal de Justicia de la Unión Europea decretó que los estados miembros pueden adoptar una normativa nacional que autorice el control jurisdiccional del carácter abusivo de las cláusulas a que se refiere el art. 4.2 de la Directiva citada ${ }^{35}$. Por otra parte, la legislación de los países escandinavos faculta expresamente al juez para evaluar y eventualmente ajustar las cláusulas principales del contrato, incluyendo aquellas relativas al precio del bien o servicio contratado ${ }^{36}$.

Asimismo, el artículo Código de Defensa del Consumidor de Brasil establece como uno de los derechos básicos del consumidor "la modificación de las cláusulas contractuales que establezcan prestaciones desproporcionadas o su revisión en razón de hechos sobrevinientes que las tornen excesivamente onerosas" (art. 6.V). Esta norma, que contiene tanto una situación de desequilibrio original en la relación de consumo (lesión) como una producida por causas sobrevinientes (imprevisión), ha sido interpretada como una autorización a los tribunales para imponer un equilibrio contractual por sobre la voluntad de las partes, incluyendo la modificación de las cláusulas relativas al precio de los bienes o servicios contratados ${ }^{37}$.

En el caso chileno, las normas del párrafo cuarto del título II de la LPC, que regulan la materia, no hacen referencia a la naturaleza de las cláusulas sometidas al control judicial, de manera que en principio no habría impedimento legal para que se incluyan en el examen de abusividad aquellas referidas al objeto principal del contrato, lo que podría implicar también la revisión de la adecuación entre el bien o servicio prestado y el precio pagado.

En este sentido, si bien es discutible que el juez pueda evaluar lo justo (abusivo) del precio, en la práctica puede intervenir en las cláusulas principales del contrato a través del análisis de cláusulas relacionadas con aquellas que determinan el objeto principal del mismo, como por ejemplo, aquellas que se refieren a pagos en caso de cumplimiento parcial de la prestación o de no utilización del servicio, las que establecen la forma de

35 Sentencia del Tribunal de Justicia de la Unión Europea, asunto C-484/2008.

36 Véase Wilhelmsson, T., "Control of Unfair Contract Terms and Social Values: EC and Nordic Approaches”, Journal of Consumer Policy, 16, 1993, pp. 435-453.

${ }^{37}$ Lima (nota 25), pp. 948-949. 
determinación del precio definitivo, etc. En otras palabras, que el juez no pueda evaluar la adecuación entre precio y retribución no implica que no pueda determinar el carácter abusivo de aquellas cláusulas que, por ejemplo, establecen el método de cálculo, las modalidades de modificación del precio u otras como las recién mencionadas ${ }^{38}$. Ello en definitiva puede significar, en el hecho, una revisión o adaptación del precio final o efectivo que se deba pagar por el consumidor, lo que a su vez puede implicar que el juez se vea en la necesidad de establecer uno diverso al estipulado originalmente en el contrato.

\section{Las facultades del Juez ante las Cláusulas abusivas}

Los artículos 16 y 16A de la LPC establecen que el efecto jurídico de la declaración de abusividad de una cláusula es su nulidad ${ }^{39}$. La LPC no señala la naturaleza de la nulidad, sin que la doctrina nacional haya discutido en profundidad el tema. Se trata de un caso expreso de nulidad parcial, en el sentido que, en principio, la nulidad afecta solo a la o las cláusulas respectivas, pero no al contrato, el cual sigue siendo válido y surtiendo efectos según sus demás estipulaciones. Solo en caso que por la naturaleza del contrato, o la intención original de las partes al celebrarlo, aquel no pueda subsistir sin las cláusulas declaradas nulas, deberá el juez declarar la nulidad del contrato.

Sin perjuicio de lo anterior, una de las mayores novedades del citado fallo de la Corte de Apelaciones de Santiago de fecha 14 de mayo de 2012 es sin duda la modificación que efectúa del contrato en relación con una de las cláusulas que declara como abusivas, rebajando el monto de la obligación a ser pagado por la consumidora en proporción a los servicios efectivamente utilizados.

Tal como se indicó, dicha sentencia estableció la rebaja del arancel anual que debía pagar la demandante, al equivalente a $20 \%$ del monto total del mismo. En otros términos, la Corte determinó una adecuación del precio acordado en relación con aquella parte de los servicios efectivamente prestados. Es interesante señalar que la Corte, si bien declara abusivas determinadas cláusulas del contrato, no declara expresamente en lo resolutivo de la sentencia la nulidad de las mismas, habiendo manifestado antes que por este carácter abusivo, "es pertinente adoptar las medidas correctivas del caso".

La decisión se aparta no solo de la jurisprudencia citada precedentemente, que en todos los casos había decretado la nulidad de las cláusulas consideradas abusivas, sino

${ }^{38}$ Informe de la Comisión Europea sobre la implementación de la Directiva 93/13 de la Unión Europea sobre las cláusulas abusivas (COM(2000), 248 final), p. 16.

${ }^{39}$ El artículo 16A de la LPC establece que "Declarada la nulidad de una o varias cláusulas o estipulaciones de un contrato de adhesión, por aplicación de alguna de las normas del artículo 16, este subsistirá con las restantes cláusulas, a menos que por la naturaleza misma del contrato, o atendida la intención original de los contratantes, ello no fuere posible. En este último caso el juez deberá declarar nulo, en su integridad, el acto o contrato sobre el que recae la declaración”. 
también del mencionado tenor de los arts. 16 y 16A de la LPC, que solo se refieren a la nulidad como sanción en estos casos. Incluso del tenor de la última parte del art. 16A podría sostenerse que la adaptación del contrato está vedada al juez, ya que en el caso que no sea posible la subsistencia del contrato con las cláusulas restantes, el juez debe declarar nulo en su integridad el acto o contrato en que se contiene la cláusula.

La referida sentencia aparece como novedosa, ya que en esta materia, como se indicó, en el derecho privado chileno, siguiendo el modelo francés, solo se permite la intervención del juez en el contrato en casos muy excepcionales. El dogma de la autonomía de la voluntad y el principio de la fuerza obligatoria del contrato son consagrados en toda su fuerza por el ya citado artículo 1545 del Código Civil, norma que es considerada por parte importante de la doctrina como el principal obstáculo para admitir la revisión judicial del contrato.

Sin perjuicio de lo anterior, debe destacarse que la última modificación a la LPC, introducida por la Ley $\mathrm{N}^{\circ} 20.555$, estableció en el art. 17E que "El consumidor afectado podrá solicitar la nulidad de una o varias cláusulas o estipulaciones que infrinjan el artículo 17 B. Esta nulidad podrá declararse por el juez en caso de que el contrato pueda subsistir con las restantes cláusulas o, en su defecto, el juez podrá ordenar la adecuación de las cláusulas correspondientes sin perjuicio de la indemnización que pudiere determinar a favor del consumidor". Se concede así expresamente la facultad al juez para adaptar el contrato con el objeto de evitar su extinción. Lamentablemente los numerales del artículo 17B establecen en su mayoría menciones obligatorias que el proveedor de servicios financieros debe incluir en el contrato, para efectos de transparencia y de su adecuada comprensión por parte del destinatario. No se ve entonces cómo podría solicitarse la nulidad o adecuación de una estipulación que infrinja el mencionado artículo, ya que justamente la infracción de la norma se producirá cuando la estipulación no ha sido incluida en el contrato, de manera que no habrá nada que anular o adecuar.

En derecho comparado, existen legislaciones que contemplan alternativas a la nulidad como sanción para las cláusulas abusivas. Así, el artículo 83 del citado Texto Refundido de la LGDCU, luego de establecer como sanción principal para las cláusulas abusivas su nulidad de pleno derecho, agrega que "el juez que declare la nulidad de dichas cláusulas integrará el contrato y dispondrá de facultades moderadoras respecto de los derechos y obligaciones de las partes”. En Argentina, el artículo 37 de la Ley No 24.240 de Defensa del Consumidor establece que en caso de declararse la nulidad de una o más cláusulas, es decir, la nulidad parcial del contrato, el juez simultáneamente deberá integrarlo si ello fuese necesario.

Asimismo, el Código de Defensa del Consumidor de Brasil reconoce en el artículo $51 \S 2$ el principio de conservación de los contratos, al establecer que "la nulidad de una cláusula contractual abusiva no invalida el contrato, excepto cuando de su ausencia, a pesar de los esfuerzos de integración, se genera una carga excesiva para cualquiera de las partes”. En principio, por tratarse de una sanción de ineficacia, esta labor de integración solo podría realizarse recurriendo a las normas supletorias contempladas en la ley. Sin embargo, se ha señalado que existe también la posibilidad que el juez recurra no solo a la legislación supletoria, sino también al contrato mismo, para suplir la cláusula 
respectiva por medio de una interpretación de la voluntad de las partes y crear una nueva (y válida) estipulación ${ }^{40}$.

El incluir la facultad judicial de integrar el contrato como efecto subsidiario o colateral de la nulidad de las cláusulas abusivas parece razonable. Si lo que se busca es preservar el contrato, de manera que la parte afectada por el comportamiento abusivo del otro contratante pueda efectivamente satisfacer el interés que le llevó a contratar, la nulidad como única sanción puede ser insuficiente. El reconocimiento de la nulidad parcial es solo el primer paso para asegurar la conservación del contrato. Además, debería otorgarse a los tribunales facultades para que, en caso de ser necesario, integren el contrato supliendo las cláusulas declaradas nulas con el derecho dispositivo y, si es preciso, a través de la interpretación integrativa de las demás estipulaciones del contrato. Ello se torna más relevante si se admite el control de las cláusulas principales del contrato o de aquellas que se les relacionan directamente, como por ejemplo las que establecen mecanismos de determinación o revisión del precio.

En el caso de los servicios, esta situación se hace más evidente, ya que muchas veces se trata de contratos de larga duración, en que las prestaciones se van devengando periódicamente o de manera continua, siendo imposible o inadecuado que la nulidad surta sus efectos normales. El caso resuelto por la Corte de Apelaciones de Santiago con fecha 14 de mayo de 2012, ya citado, proporciona el ejemplo perfecto. En el caso, la estudiante había ya cursado la asignatura que le faltaba para obtener la titulación, titulación que se condicionaba por el prestador del servicio, a base de la transcrita cláusula segunda, al pago del arancel de un semestre completo sin importar el número de asignaturas efectivamente cursadas. La mera declaración de nulidad de dicha cláusula implicaba en la práctica dos alternativas. La primera, la terminación del contrato, ya que dicha cláusula establece la forma en que, en determinados supuestos, se determinaría el precio por los servicios contratados, de manera que el acuerdo no podría subsistir sin ella al afectar una cláusula esencial del contrato. Por cierto, esta alternativa tiene consecuencias nefastas para la parte afectada, quien en el caso particular vería frustrada su legítima expectativa de obtener un título universitario. La segunda, integrar el contrato de modo de ajustarlo a las expectativas razonables y el interés perseguido por las partes (especialmente la perjudicada, por la cláusula abusiva), de manera que la declaración de nulidad de la cláusula abusiva no produzca perjuicios mayores que los que se han tratado de evitar con dicha declaración.

La Corte, al resolver la cuestión, siguió la segunda alternativa, adaptando el precio del contrato, en razón de la abusividad de la cláusula que regulaba su determinación para el caso de utilización parcial de los servicios. Lamentablemente, la sentencia es pobre en cuanto a la explicitación de los fundamentos de dicha opción, y especialmente respecto de los parámetros utilizados para la adecuación del contrato, cuestión que es analizada en el apartado siguiente. 


\section{Algunas consideraciones sobre los Criterios PARA LA MODIFICACIÓN JUDICIAL DEL CONTRATO}

Más allá de la discusión respecto de la legitimidad o no de los tribunales para revisar los contratos, y atendida la tendencia jurisprudencial referida anteriormente, es importante detenerse en la extensión, límites y método a los que el juez debe sujetarse al momento de adaptar el contrato ${ }^{41}$.

Para estos efectos, hay que precisar que el problema se presenta esencialmente cuando la revisión judicial ha recaído sobre las cláusulas referidas al objeto principal del contrato, especialmente en lo que se refiere al precio pactado por el bien o servicio que se provee. Lo mismo puede decirse de cláusulas directamente relacionadas con el precio, como por ejemplo las que establezcan sistemas de reajustabilidad del mismo. Si las cláusulas se refieren a otro tipo de derechos u obligaciones, por ejemplo aquellas que establezcan inversiones de la carga de la prueba o exenciones de responsabilidad, bastará integrar el contrato con las normas dispositivas provistas por la legislación correspondiente, ya que se entiende que ellas son las consideradas como justas por el legislador en caso de silencio de las partes.

Respecto de la extensión y límites de las atribuciones del juez, usualmente se sostiene que la adaptación del contrato no puede significar la alteración esencial de la naturaleza del acuerdo celebrado por las partes, de manera que en definitiva resulte completamente diverso al originalmente celebrado por los contratantes; por ejemplo, cambiando el objeto de la prestación de una o ambas partes ${ }^{42}$.

Un problema más complejo es determinar un método que entregue parámetros y criterios que pueda utilizar el juez para adaptar el contrato. En derecho comparado las normas que admiten la revisión del contrato por el juez generalmente no entregan parámetros ni reglas para tales efectos, sino que hacen referencia a principios generales. Así por ejemplo, en relación con la adaptación del contrato por cambio de circunstancias, los PECL hablan de una distribución justa y equitativa de las pérdidas y ganancias entre las partes, y el DCFR (Draft Common Frame of Reference) se refiere a una razonable y equitativa modificación de la obligación de la parte afectada ${ }^{43}$. La citada propuesta de Reglamento de Normativa Común de Compraventa Europea hace referencia en su artículo 89 a lo que las partes habrían razonablemente acordado al momento de la celebración del contrato si hubieran tenido en cuenta el cambio de circunstancias. En el mismo sentido, los códigos italiano (art. 1467) y argentino (art. 1198) hablan de la modificación equitativa del contrato para estos casos.

$\mathrm{Al}$ efecto, la doctrina extranjera ha sugerido una serie de alternativas para resolver el problema, todas ellas dirigidas a que la adaptación del contrato conlleve a una adecuada

41 Para un análisis mayor del tema, véase Momberg, R., "El sistema de remedios para el caso de imprevisión o cambio de circunstancias”, en Incumplimiento contractual: nuevas perspectivas. Cuadernos de análisis jurídicos VII, Santiago, Ediciones Universidad Diego Portales, 2011.

${ }^{42}$ Véase Principles of European Contract Law, Comentarios Oficiales, p. 117.

${ }^{43}$ PECL, artículo 6:111; y DCFR, artículo III.- 1:110. 
distribución de los costos entre las partes, evitando el simple y completo traslado de tales costos de una parte hacia la otra. La naturaleza y finalidad del negocio, junto con las expectativas razonables de las partes, surgen nuevamente como criterios principales para la modificación. Así, la modificación debe tender a la satisfacción del interés razonable de la parte afectada (en este caso por las cláusulas abusivas), pero sin que ello implique una carga excesiva o injustificada para el proponente. No se trata de sancionar, por esta vía, al contratante abusivo, sino de adaptar el acuerdo para que responda efectivamente a la naturaleza del negocio y al interés razonable de los contratantes. Debe al efecto recordarse que sin perjuicio de la nulidad de las cláusulas abusivas, al menos en el caso de relaciones de consumo, el proveedor infractor estará sujeto a multas administrativas y podría además ser condenado a indemnizar los perjuicios que su conducta ilícita ha producido al consumidor.

En este sentido, no debe olvidarse que lo sancionado en el artículo 16 letra g) de la LPC es el desequilibrio importante en las contraprestaciones, por lo que el objetivo último de la intervención judicial a través del control de las cláusulas abusivas debería ser justamente la restauración del equilibrio entre los derechos y obligaciones recíprocas, aunque ello implique la modificación del contrato. La misma norma entrega dos parámetros iniciales para dicha restauración: la finalidad del contrato y las normas especiales o generales que lo rigen. El primer parámetro implica un examen interno de la relación contractual, que responde a la satisfacción del interés razonable de las partes. El segundo parámetro implica un examen externo, referido a la normativa legal supletoria que podría integrar el contrato en lugar de la cláusula declarada como abusiva.

En el caso en comento, la Corte de Apelaciones de Santiago siguió el más simple (y menos adecuado) sistema de distribución de costos: la simple equivalencia aritmética entre el precio total pactado y el servicio efectivamente utilizado. Así, siendo de cinco cursos la malla normal, al solo tomarse uno, la Corte rebajó el arancel al equivalente al $20 \%$ de su valor total. Es evidente la falta de rigurosidad de un criterio como este, que no considera la estructura completa de costos que se ha tomado en cuenta al momento de la fijación del precio por parte del proveedor; así como tampoco los bienes o servicios, anexos al principal, que también son aprovechados por el consumidor en el marco de la relación contractual.

La adaptación del contrato es una tarea compleja, de modo que el "equilibrio entre las prestaciones" que pretenden satisfacer los fallos citados no puede aplicarse de manera ligera al momento de proceder a la adaptación del acuerdo. Si bien un desequilibrio importante entre las contraprestaciones debe considerarse como antecedente relevante para determinar la abusividad de una cláusula, la restauración de tal equilibrio implica que el juez deba examinar los términos del acuerdo más allá de una simple correlación aritmética entre el objeto de la prestación de una de las partes y el precio que la otra paga por dicha prestación, aplicando los criterios y parámetros mencionados en los párrafos anteriores, de manera de realizar un análisis más complejo y completo de la relación contractual. Tal como se indicó, no se trata simplemente del traslado de los costos o riesgos de una parte a la otra, sino de corregir el desequilibrio significativo entre las contraprestaciones, evitando que esta corrección imponga sacrificios, cargas u obligaciones 
excesivas a una de las partes. Si así fuese, se estaría contrariando a la equidad, principio que justamente la normativa del Párrafo $4^{\circ}$ del Título II de la LPC busca proteger ${ }^{44}$.

\section{Conclusiones}

El presente estudio ha demostrado la insuficiencia de la normativa vigente para el control efectivo de las cláusulas abusivas, cuestión ya planteada por la doctrina nacional ${ }^{45}$. Esta insuficiencia tiene lugar principalmente en relación con los efectos de la declaración de abusividad de una o más cláusulas, los cuales están limitados legalmente a la nulidad de las mismas. Es preciso entregar al juez la facultad de integrar el contrato, adaptándolo si es necesario, supliendo las cláusulas declaradas nulas con el derecho dispositivo o por medio de la interpretación integrativa de las demás estipulaciones del contrato. Solo de esta manera se logrará cumplir con el principio de conservación del contrato, permitiendo que este mantenga su utilidad como instrumento jurídico y económico de satisfacción de los intereses razonables y legítimos de las partes.

En tanto las modificaciones legales no se produzcan, es labor de los tribunales establecer los criterios que mejor respondan al interés legítimo de la parte afectada por la conducta abusiva de la otra. En este sentido, en relación con el control de las cláusulas abusivas sería recomendable que la jurisprudencia explicitara de mejor manera tanto los fundamentos en virtud de los cuales una determinada cláusula puede ser declarada abusiva como la naturaleza de los efectos jurídicos que dicha declaración produce respecto de las obligaciones de las partes y del contrato.

Una última reflexión. Nuevamente el derecho del consumo se ha transformado en un elemento transformador del derecho privado tradicional, esta vez alterando uno de los principios quizás más firmemente defendidos por la doctrina tradicional, cual es la intangibilidad del contrato.

Ello en sí no representa un problema, y de hecho es un fenómeno que ya ha sido destacado por la doctrina comparada ${ }^{46}$. Sin embargo, la falta de análisis dogmático y en especial el hecho de que en nuestro país el derecho del consumo se haya transformado en un derecho esencialmente circunstancial, cuyas normas están sujetas más bien a necesidades contingentes que a principios jurídicos de general aplicación, puede generar que las decisiones judiciales adolezcan de sustento dogmático suficiente, convirtiéndose en un derecho casuístico y de difícil predicción.

${ }^{44}$ Dicho párrafo se titula "Normas de equidad en las estipulaciones y en el cumplimiento de los contratos de adhesión".

45 Véase Pizarro, C., "El fracaso de un sistema. Análisis empírico y dogmático del control de las cláusulas abusivas en contratos por adhesión”, en Revista de Derecho (Valdivia), v. XX, No 2, 2007, pp. 31-47.

46 Véase Hondius, E., "The innovative nature of consumer law. Ius commune lecture 2010”, Journal of Consumer Policy, 35, 2012, pp. 165-173. 


\section{BIBLIOGRAFÍA}

Abeliuk, R., Las obligaciones, 4ª Edición, Ed. Jurídica de Chile, Santiago, 2001.

BARCIA, R., “¿Es posible construir la teoría general del contrato desde la excepción? La revisión judicial del contrato", en Sesquicentenario del Código Civil de Andrés Bello: Pasado, Presente y Futuro de la Codificación, LexisNexis, Santiago, 2005.

BARCia R., "La autonomía privada como principio sustentador de la teoría del contrato y su aplicación en Chile", en Temas de Contratos. Cuadernos de análisis jurídico, Colección Derecho Privado III, Ediciones Universidad Diego Portales, Santiago, 2006.

Dawson, J., "Judicial Revision of Frustrated Contracts: The United States", Boston University law review 64, 1, 1984.

De la MAza, I., "Contratos por adhesión y cláusulas abusivas ¿Por qué el Estado y no solamente el mercado?", en Revista Chilena de Derecho Privado, No 1, 2003.

De la Maza, I., "El control de las cláusulas abusivas y la letra g)", Revista Chilena de Derecho Privado, $\mathrm{N}^{\circ}$ 3, 2004.

Dörr, J.C. "Notas acerca de la teoría de la imprevisión”, Revista Chilena de Derecho, V. 12, 1985.

Elorriaga, F., "La nulidad parcial", en Revista de Derecho y Jurisprudencia, Edición Bicentenario, Doctrinas Esenciales, Santiago, Editorial Jurídica, 2010.

Fueyo, F., "La ejecución de buena fe, del art. 1546 del Código Civil, es uno de los requisitos legales del pago y como tal se proyecta como fundamento de la indexación y desindexación”, en Fueyo, F. (Ed.), Instituciones De Derecho Civil Moderno. Ed. Jurídica de Chile, Santiago, 1990.

GHestin, J., Le prix dans les contrats de longue durée. LGDJ, Paris, 1990.

Hondius, E., "The innovative nature of consumer law. Ius commune lecture 2010", Journal of Consumer Policy, 35, 2012.

Informe de la Comisión Europea sobre la implementación de la Directiva 93/13 de la Unión Europea sobre las cláusulas abusivas (COM(2000), 248 final).

Lima Marques, C., Contratos no Código de Defesa do Consumidor, 6 ${ }^{a}$ Ed., Editora Revista dos Tribunais, São Paulo, 2011.

López, J., Las obligaciones y contratos frente a la inflación, Ed. Jurídica de Chile, Santiago, 1978.

LóPEZ, J., Los contratos: parte general, Ed. Jurídica de Chile, Santiago, 2001.

Mazeaud, D. y Sauphanor-Brouillaud, N., "Unfair contract terms", en Schulze, R. (ed.), Common European Sales Law - Commentary, Nomos Verlagsgesellschaft, Baden-Baden, 2012.

Meli, M., "Unfair Terms and Unfairness Test in Contracts between Businesses and Consumers", en Somma, A. (ed.), The Politics of the Draft Common Frame of Reference, Kluwer Law International, Alphen aan den Rijn, 2009.

Momberg, R., “Teoría de la imprevisión: la necesidad de su regulación legal en Chile”, Revista Chilena de Derecho Privado, No 15, 2010.

Momberg, R., "El sistema de remedios para el caso de imprevisión o cambio de circunstancias", en Incumplimiento contractual: nuevas perspectivas. Cuadernos de análisis jurídicos VII, Santiago, Ediciones Universidad Diego Portales, 2011.

Peñailillo, D., "La revisión judicial de obligaciones y contratos en la reforma del Código Civil: la lesión y la imprevisión”, Revista de Derecho (Concepción), 2000.

Pizarro, C., "El fracaso de un sistema. Análisis empírico y dogmático del control de las cláusulas abusivas en contratos por adhesión”, en Revista de Derecho (Valdivia), v. XX, No 2, 2007.

Whittaker, S., "Unfair Contract Terms, Unfair Prices and Bank Charges", The Modern Law Review, (2011) 74(1).

Wilhelmsson, T., "Control of Unfair Contract Terms and Social Values: EC and Nordic Approaches", Journal of Consumer Policy, 16, 1993.

Zimmermann, R., The law of obligations: Roman foundations of the civilian tradition, Oxford University Press, Oxford, 1996. 